\title{
Marcos regulatórios estaduais em saneamento básico no Brasil*
}

\author{
Alceu de Castro Galvão Junior** \\ Sandra Regina Nishio*** \\ Beatriz Baraúna Bouvier**** \\ Frederico Araujo Turolla*****
}

\begin{abstract}
Sumário: 1. Introdução; 2. Metodologia; 3. O papel institucional dos estados no saneamento; 4. Políticas públicas de água e esgoto; 5 . Políticas estaduais de saneamento; 6. Discussão; 7. Conclusão.
\end{abstract}

Summary: 1. Introduction; 2. Methodology; 3. The states' institutional roles in sanitation; 4. Public policies on water and sewage; 5. State policies on sanitation; 6. Discussion; 7. Conclusion.

Palavras-chave: saneamento; política pública; marcos regulatórios setoriais; regulação; políticas estaduais.

KEY wORDs: sanitation; public policy; regulatory frameworks for the sector; regulation; state policies.

Este artigo analisa os marcos regulatórios estaduais para o setor de saneamento básico. A pesquisa documental identificou a presença de leis estaduais em apenas

\footnotetext{
* Artigo recebido em jan. 2007 e aceito em maio 2008. Os autores agradecem a Fundação Cearense de Apoio ao Desenvolvimento Científico e Tecnológico (Funcap) e a Fundação de Amparo à Pesquisa do Estado de São Paulo (Fapesp).

** Engenheiro civil, mestre em hidráulica e saneamento pela Escola de Engenharia de São Carlos da Universidade de São Paulo (EESC/USP), doutorando da Faculdade de Saúde Pública (FSP/USP), analista da Agência Reguladora do Ceará (Arce). Endereço: Rua Marcos Macedo, 1350, ap. 702 _ CEP 60150-190, Fortaleza, CE, Brasil. E-mail: alceugalvao@uol.com.br.

*** Bióloga, doutoranda do Instituto de Ciências Biomédicas da USP (ICB/USP). E-mail: snishio@ usp.br.

**** Arquiteta, mestranda da Faculdade de Saúde Pública (FSP/USP). E-mail: bbarauna@ hotmail.com.

***** Economista, doutor em economia de empresas pela Fundação Getulio Vargas (FGV-SP). Professor de economia da FGV e da Escola Superior de Propaganda e Marketing (ESPM). E-mail: fturolla@fgvsp.br.
} 
cinco estados (São Paulo, Minas Gerais, Rio Grande do Sul, Rio Grande do Norte e Goiás). Os marcos legais estaduais são descritos quanto a um conjunto de atributos ou funções selecionadas: universalização, instrumentos financeiros, regulação e controle social. A principal conclusão é que o desenvolvimento dessas políticas, assim como sua regulamentação, encontra-se em estágio incipiente e poderá receber impulso com aprovação de nova lei federal de dezembro de 2006.

\section{State regulatory frameworks for basic sanitation in Brazil}

This paper analyzes state regulatory frameworks for the water and sanitation sector in Brazil. The documental research identified that only five states have their own policies (São Paulo, Minas Gerais, Rio Grande do Sul, Rio Grande do Norte, and Goiás). The frameworks are described according to a selected set of attributes, namely: universal access to water and sanitation, financial instruments, regulation and social control. The main conclusion is that the policies under study are in an early stage of development and may receive a boost from the approval of new federal legislation in December 2006.

\section{Introdução}

O papel dos estados em relação a saneamento é objeto de controvérsia jurídica. A Constituição Federal de 1988 garante a competência do município para a prestação dos serviços de interesse local. ${ }^{1}$ Entretanto, a divergência sobre os serviços que se enquadrariam no interesse local torna razoavelmente complexa a definição da competência dos diversos níveis de poder com relação aos sistemas de saneamento. Essa competência é difusa na Constituição Federal de 1988 e nas leis que regulam o assunto. As leis estaduais que dispõem sobre a matéria vêm sendo questionadas por ações de inconstitucionalidade no Supremo Tribunal Federal. ${ }^{2}$

No arranjo federativo explicitado na Constituição de 1988, os estados têm importante papel, definido no $\S 1^{\circ}$ o do art. 25, que apresenta a chamada "competência residual", assegurando a eles as competências que não lhes sejam vedadas pelo texto constitucional. No $§ 2^{\circ}$ do mesmo artigo, os estados receberam a competência dada por emenda constitucional de 1995 de explorar

\footnotetext{
${ }^{1} \mathrm{O}$ inciso $\mathrm{V}$ do art. 30 define que compete aos municípios "organizar e prestar, diretamente ou sob regime de concessão ou permissão, os serviços públicos de interesse local, incluído o de transporte coletivo, que tem caráter essencial". Note-se que enquanto o transporte coletivo tem sua competência claramente atribuída aos municípios, o mesmo não se pode dizer com relação ao saneamento.

${ }^{2}$ Duas ações importantes nesse aspecto são a $\mathrm{ADin}$ ํㅜ 2.077 e a $\mathrm{ADin}$ ํo $\mathbf{1} .842$.
} 
os serviços locais de gás canalizado, que se soma à sua capacidade de instituir regiões metropolitanas, aglomerações urbanas e microrregiões. A competência sobre serviços de saneamento não pode ser identificada com a mesma clareza que a dos serviços de gás canalizado.

Assim, a federação brasileira comporta a existência de marcos regulatórios estaduais em setores cuja titularidade não é claramente definida como federal ou municipal, ainda que haja controvérsia sobre vários aspectos de sua validade. Este artigo abstrai a discussão jurídica subjacente e realiza avaliação sobre o estágio dos marcos regulatórios que puderam ser identificados nos estados brasileiros. Em uma pesquisa documental foi identificada a presença de marcos regulatórios em apenas cinco estados, o que sugere que a atividade legislativa estadual nesse campo, assim como as políticas públicas respectivas, encontram-se em estágio incipiente no Brasil.

$\mathrm{O}$ artigo foi organizado em seis seções, além desta introdução. A seção 2 apresenta a metodologia de pesquisa. A seção 3 discute o papel institucional dos estados brasileiros no setor de saneamento básico em uma perspectiva histórica. A seção 4 apresenta uma investigação sobre os aspectos constitutivos de uma política de água e esgoto. A seção 5 apresenta os resultados da pesquisa documental, descrevendo as políticas estaduais que foram identificadas. A seção 6 discute os resultados e a seção final apresenta conclusões do estudo.

\section{Metodologia}

Para este artigo foi utilizado estudo documental mediante pesquisa das políticas públicas estaduais de água e esgoto. A pesquisa foi realizada em 2006 e foram obtidos documentos em sites oficiais dos governos estaduais e na literatura técnico-científica. Dos 26 estados brasileiros, foram encontradas disponibilizadas em meio digital as políticas públicas de cinco estados: Goiás, Minas Gerais, Rio Grande do Norte, Rio Grande do Sul e São Paulo.

$\mathrm{O}$ estudo foi realizado em duas etapas. A primeira levantou aspectos do papel institucional dos estados brasileiros no setor de saneamento. A segunda parte do estudo apresenta descrição de cada política quanto a um conjunto de atributos ou funções selecionadas: universalização, instrumentos financeiros, regulação e controle social. A partir dessas informações, os dados foram comparados e foram feitas a interpretação, a discussão e a conclusão do estudo. A discussão e conclusão centraram-se principalmente no conteúdo da política e não na sua implementação. 
Apesar de algumas políticas tratarem do saneamento ambiental, relacionado à água, esgoto, resíduos sólidos, drenagem e controle de vetores, este artigo limitou-se aos serviços de abastecimento de água e esgotamento sanitário. Tal definição leva em conta as peculiaridades desses serviços, que são típicos monopólios naturais e geralmente prestados por meio de concessão e pagamento por tarifas, relativamente aos demais que compõem o saneamento ambiental.

\section{O papel institucional dos estados no saneamento}

A participação de alguns estados no setor de saneamento é relativamente antiga. Por exemplo, Whitaker (1991) relata a participação de governos estaduais como o do estado de São Paulo. O mesmo autor relata modelos bem-sucedidos em que departamentos estaduais centralizaram desde o planejamento e execução das obras até a operação dos serviços.

O Planasa - Plano Nacional de Saneamento constituiu marco da participação dos estados na provisão e operação da infraestrutura de saneamento no Brasil. Em 1967, o Banco Nacional da Habitação (BNH) foi encarregado de realizar o diagnóstico inicial da situação do setor. Foram criados fundos de água e esgoto estaduais (FAEs), além de programas estaduais trienais. $\mathrm{O}$ financiamento aos municípios passou a ser realizado conjuntamente pelo $\mathrm{BNH}$ e pelos governos estaduais, com contrapartida obrigatória dos municípios e com a obrigação de que estes organizassem os serviços na forma de autarquia ou sociedade de economia mista. Entretanto, na prática, o financiamento acabou não sendo feito em proporções iguais pelo BNH e estados. De 1968 a 1984, conforme Oliveira e Sanchez (1996), apenas 35\% dos recursos se originaram nos fundos estaduais, enquanto os $65 \%$ restantes foram fornecidos pelo $\mathrm{BNH}$. Além do financiamento, outro importante aspecto da participação dos estados foi a criação das Companhias Estaduais de Saneamento Básico (Cesbs), organizadas sob a forma de sociedade anônima, que deveriam obter as concessões diretamente do poder concedente, as autoridades municipais.

Para Turolla (1999), a experiência do Planasa foi bem-sucedida no sentido de gerar uma rápida expansão da cobertura dos serviços de saneamento no Brasil, ainda que insuficiente para atender às demandas geradas pelo processo de urbanização bastante recente do país. Contudo, o modelo engendrado pelo Planasa foi caracterizado pela ineficiência operacional, fortemente relacionado com a sua ênfase na construção dos sistemas em detrimento da criação de condições adequadas para a operação. O modelo funcionou en- 
quanto as fontes de financiamento da expansão dos sistemas geravam um fluxo líquido positivo. O esgotamento veio quando o fluxo de novos recursos reduziu-se consideravelmente. Nesse momento, as companhias estaduais de água e esgoto viram-se obrigadas a arcar com despesas financeiras elevadas em decorrência das dívidas contraídas na etapa anterior, enquanto operavam sistemas com baixo grau de eficiência operacional.

Entre os setores da infraestrutura brasileira, o abastecimento de água e o esgotamento sanitário são os que mais têm apresentado dificuldades econômicas e institucionais, com repercussão nos índices de atendimento e na qualidade dos serviços. Entre os principais problemas do setor estão a baixa eficiência operacional, a insuficiência de investimentos, a ausência de regulação e de controle social e a presença de déficit de atendimento, especialmente no tocante à coleta e tratamento de esgotos sanitários. Nascimento e Heller (2005) destacam como responsáveis pelo déficit dos serviços os seguintes fatores: a fragmentação de políticas públicas, com múltiplos agentes e baixo nível de integração das ações; os problemas relacionados com a concessão e a regulação dos serviços, envolvendo o poder concedente e a concessionária; a carência de instrumentos de regulamentação e de regulação; e a ausência de continuidade administrativa e de mecanismos que assegurem a implantação de ações e regulamentos oriundos do planejamento.

As dificuldades institucionais são agravadas pela inexistência de uma política nacional para o setor de água e esgotos que aponte para a retomada dos investimentos, a regulação, o controle social e a universalização dos serviços. O agravamento da crise institucional tornou-se mais evidente nos últimos cinco anos, quando do vencimento dos contratos de concessão assinados à época do Planasa. Concessionárias e municípios têm travado disputas políticas e jurídicas em torno do processo de renovação de grande número de contratos de concessão, o que gera instabilidade aos investimentos.

Assim, a não existência de uma política nacional para o setor e as indefinições acerca da titularidade dos serviços prejudicam o estabelecimento de políticas estaduais e municipais. Na opinião de Ogera e Phillipi Jr. (2005), a definição de políticas públicas de saneamento por estados e municípios sem a existência de um marco federal leva ao estabelecimento de políticas desarticuladas, tanto em âmbito de governo como entre setores de planejamento.

Outra consequência da ausência de um marco legal nacional é a pulverização das ações governamentais, reduzindo a eficiência e a eficácia dos investimentos. Conforme aponta Costa (2003), em 2002 havia oito ministérios e 17 órgãos federais que desenvolviam ações relativas ao saneamento ambiental, na formulação de programas e políticas de saneamento e na operacionalização 
dos recursos. A criação do Ministério das Cidades em 2003 representou um avanço institucional, pois foi aberto um canal para a integração das políticas de desenvolvimento urbano, por meio da Secretaria Nacional de Saneamento Ambiental, mas mesmo após sua criação as políticas ainda permanecem desarticuladas.

Houve diversas tentativas de criação de lei nacional sobre saneamento básico. As mais recentes foram um projeto de lei de iniciativa do Executivo Federal (PL no 5.296/2005) e um projeto apresentado no Senado pelo senador Gérson Camata. Em 2006, os dois projetos deram origem a uma comissão conjunta que gerou um substitutivo, cujo texto foi aprovado naquele ano nas duas casas legislativas. Até a aprovação desse projeto de lei, a ausência de lei nacional sobre normas gerais de saneamento básico reforçou o papel da competência legislativa estadual. Assim, a investigação ora desenvolvida tem como objetivo identificar e analisar políticas públicas estaduais para os serviços de água e esgoto no país em face da ausência do marco regulatório federal.

\section{Políticas públicas de água e esgoto}

Esta seção investiga os aspectos constitutivos de uma política de água e esgoto. Soares e colaboradores (2003), ao proporem um modelo conceitual para os serviços, consideraram principais componentes: os aspectos institucionais, os mecanismos de investimento e de alocação de recursos financeiros, os fatores econômicos determinantes e o desenvolvimento de sistemas de esgoto sanitários. Turolla (2002) entende como pontos relevantes para a discussão de políticas públicas voltadas para o setor de saneamento: o marco legal e a questão da titularidade; a regulação; a universalização; a participação e financiamento da iniciativa privada; a participação dos usuários; e o pagamento de outorga. Faria e Faria (2004), ao discutirem cenários e perspectivas para o setor de saneamento, destacaram que uma lei sobre política do setor deve tratar de ajustes de competência entre as esferas de governo, regulação e a fiscalização de serviços sob concessão, construção de um fundo de investimento para o setor, e normatização de procedimentos de revisão tarifária.

No entanto, segundo estudo do Ministério do Planejamento e Orçamento, dentro de um novo modelo de gestão o Estado deve exercer suas funções de financiamento, prestação dos serviços e controle social (Brasil, 1995a). No mencionado estudo, a função de financiamento é entendida como o conjunto dos dispositivos para garantir os recursos necessários para financiar os investimentos, custeio e remuneração do setor de saneamento. Na função da prestação dos serviços desta- 
cam-se a necessidade de se separar as atividades de regulação e gestão da prestação dos serviços. O controle social se refere à instituição de um nível de controle pela sociedade e pelos usuários sobre os serviços de saneamento.

No aspecto de elaboração de políticas estaduais, Moraes e Borja (2001) sugerem que para o estado da Bahia a política deve ser norteada pelos princípios da universalização, equidade, integralidade, titularidade municipal, gestão pública, participação e controle social. Esses autores ressaltam que, em virtude da ausência de uma política pública estadual, os programas e projetos no estado da Bahia resultam em ações fragmentadas e permanece a distribuição desigual dos serviços de saneamento.

\section{Políticas estaduais de saneamento}

Entre os estados analisados neste artigo, São Paulo foi o primeiro a criar uma política estadual em 1992, seguido por Minas Gerais (1994), Rio Grande do Sul (2003), Rio Grande do Norte e Goiás (2004). As cinco políticas estaduais têm como objetivos assegurar a salubridade da população e do ambiente e promover o planejamento e desenvolvimento do setor de saneamento em cada estado. Na tabela 1 estão as principais características dos estados em análise.

Tabela 1

Características sanitárias dos estados

\begin{tabular}{|lccccc|}
\hline Estado & Habitantes* & $\begin{array}{c}\text { Abastecimento } \\
\text { de água (\%)** }\end{array}$ & $\begin{array}{c}\text { Esgotamento } \\
\text { sanitário (\%)** }\end{array}$ & $\begin{array}{c}\text { Universalização } \\
\text { (R\$ milhões)*** }\end{array}$ & $\begin{array}{c}\text { Lei estadual } \\
\text { relevante }\end{array}$ \\
\hline São Paulo & 40.442 .795 & 98,3 & 89,8 & $39.471,23$ & $7.750 / 1992$ \\
Minas Gerais & 19.237 .450 & 96,1 & 84,6 & $17.307,18$ & $11.720 / 1994$ \\
$\begin{array}{l}\text { Rio Grande } \\
\text { do Sul }\end{array}$ & 10.845 .087 & 93,1 & 15,7 & $12.366,41$ & $12.037 / 2003$ \\
$\begin{array}{l}\text { Rio Grande } \\
\text { do Norte }\end{array}$ & 3.003 .087 & 91,2 & 17,0 & $2.288,26$ & $8.485 / 2004$ \\
Goiás & 5.619 .917 & 82,7 & 36,0 & $7.090,68$ & $14.939 / 2004$ \\
\hline
\end{tabular}

*IBGE, 2006 - Estimativa populacional para o ano de 2005.

**IBGE, 2005 - Síntese de indicadores sociais 2004. Abastecimento de água: canalização interna para pelo menos um cômodo do domicílio particular permanente, decorrente de rede geral de distribuição. Esgotamento sanitário: quando a canalização das águas servidas ou dos dejetos é ligada a um sistema de coleta que os conduz para o desaguadouro geral da área, região ou município, mesmo que o sistema não tenha estação de tratamento da matéria esgotada.

*** Brasil, 2003 - Custo da universalização para o ano de 2020. 
A seguir são descritas as políticas dos estados selecionados nas funções: universalização, instrumentos financeiros, regulação e controle social.

\section{São Paulo}

A política estadual de saneamento de São Paulo tem por finalidade disciplinar o planejamento e a execução das ações, obras e serviços de saneamento no estado (São Paulo, 1992). Quanto à universalização do saneamento, a política apresenta o princípio do direito de todos sobre o ambiente salubre e à melhoria da qualidade de vida, impondo-se ao poder público e à coletividade o dever de assegurá-lo. Esse princípio é ratificado no objetivo da política ao assegurar os benefícios da salubridade ambiental à totalidade da população do estado.

Para a execução da política estadual são usados como instrumentos o Plano Estadual de Saneamento, o Sistema Estadual (Sesan) e o Fundo Estadual (Fesan).

O plano estadual é o conjunto de elementos de informação, diagnóstico, definição de objetivos, metas e instrumentos, programas que integram o planejamento e a execução das ações de saneamento no estado. Elaborado com base em planos regionais de saneamento ambiental, o plano é quadrienal e aprovado por lei.

Entre as principais funções do Sesan estão a elaboração, execução e atualização do plano estadual, a promoção do afluxo de recursos financeiros e a formulação e implantação de mecanismos de gestão que assegurem a aplicação racional de recursos públicos.

Conforme consta na política estadual, o Fesan é caracterizado como o "instrumento institucional de caráter financeiro destinado a reunir e canalizar recursos financeiros para a execução dos programas do Plano Estadual de Saneamento". As origens dos recursos do fundo são provenientes de alocações orçamentárias específicas; transferência da união destinada à execução de planos e programas decorrentes da política nacional de saneamento; transferências de outros fundos estaduais para a realização de obras e serviços de saneamento de interesse comum; empréstimos e outras contribuições financeiras; retorno das operações de crédito contratadas, entre outros.

Como instrumentos de controle social, foram criados órgãos colegiados consultivos e deliberativos, de nível estratégico, sendo o Conselho Estadual de Saneamento (Conesan), de nível central, e as Comissões Regionais de Saneamento Ambiental (Cresan), de nível regional. Entre as atribuições do Conesan estão a discussão e aprovação de propostas de projetos de lei referentes ao 
plano estadual, a aprovação do relatório anual sobre a "situação de salubridade ambiental no estado" e o estabelecimento de diretrizes para a formulação de programas anuais de aplicação de recursos do Fesan. Ao Cresan cabe a aprovação do Plano Regional de Saneamento, a apreciação do relatório anual sobre "a situação de salubridade ambiental da região" e o acompanhamento da aplicação dos recursos financeiros do Fesan, em seu âmbito.

Dos instrumentos da política, somente o Conesan foi regulamentado (Decreto $n^{\circ}$ 41.679, de 31de março de 1997). Segundo estudo sobre universalização no estado (São Paulo, 2003:14)

a situação institucional evidencia a necessidade de se implementar o modelo previsto nos mecanismos legais existentes, conforme definido na Lei $\mathrm{n}^{\mathrm{o}}$ 7.750/92, para a gestão dos serviços de saneamento básico, e de se formular as diretrizes básicas e as estratégias para sua total implantação com vistas à universalização e à adequada prestação dos serviços.

Para Ogera e Philippi Jr. (2005) como consequência da não implementação do Plano Estadual de São Paulo, municípios do estado têm estabelecido suas políticas próprias, muitas vezes desarticuladas da política estadual.

Em complementação à política estadual editada em 1992, o governo de São Paulo instituiu a Comissão de Regulação de Saneamento do Estado de São Paulo (Corsanpa) por meio do Decreto no 50.868, de 8 de junho de 2006. Entre as competências da Corsanpa incluem-se a regulação e fiscalização dos serviços de titularidade estadual; a execução da política tarifária estabelecida pelo Conesan; e o acompanhamento de planos executivos de expansão e de metas ambientais conforme a lei do plano estadual (São Paulo, 2006).

\section{Minas Gerais}

No tocante à universalização dos serviços de saneamento, a política pública do estado de Minas Gerais estabelece como princípio o direito de todos ao saneamento básico (Minas Gerais, 1994). Entre as diretrizes da política, prevê-se "a adoção de mecanismos que propiciem à população de baixa renda o acesso aos serviços" e "a solução dos problemas de saneamento básico em áreas urbanas faveladas ou em outras de situação irregular".

Os instrumentos financeiros e o controle social dos serviços são tratados no âmbito do sistema estadual de saneamento básico, definido como o conjunto de agentes institucionais que trabalham de forma articulada e cooperada 
para a formulação de políticas, definição das estratégias e execução das ações de saneamento básico. Dentro do sistema, os instrumentos financeiros são orientados pelo Plano Estadual de Saneamento Básico (Pesb), que estabelecerá objetivos e diretrizes, metas de curto e médio prazos, cronograma de execução das ações, definição dos recursos financeiros, entre outros. O Fundo Estadual de Saneamento Básico (Fesb), previsto na política, foi extinto em 2001, por meio da Lei no 13.848. Seus recursos foram destinados ao Banco de Desenvolvimento de Minas Gerais S.A. (BDMG) para aplicação em saneamento básico em consonância com as diretrizes da política estadual. Conforme previsto, o plano estadual deverá ser instituído por lei.

O controle social é definido como princípio na política, ficando a criação do Conselho Estadual de Saneamento Básico (Cesb), órgão colegiado de nível estratégico superior ao sistema estadual. Não há menção a mecanismos de regulação na política.

\section{Rio Grande do Sul}

Na política estadual do Rio Grande do Sul, a universalização, tratada como o ambiente salubre, indispensável à segurança sanitária e à melhoria da qualidade de vida, é considerada direito de todos, impondo-se ao poder público e à coletividade o dever de assegurá-la. Na formulação das políticas públicas do estado, serão estabelecidas metas quanto à cobertura pelos sistemas públicos de abastecimento de água potável e de esgotamento sanitário (Rio Grande do Sul, 2003).

Entre os instrumentos da política estadual, destacam-se o sistema, o plano e o fundo estaduais de saneamento. O sistema estadual tem como função básica a elaboração, execução e atualização do plano estadual, a proposição do afluxo de recursos financeiros para o saneamento do estado e a proposição e implantação de mecanismos de gestão que assegurem a aplicação racional de recursos financeiros. Ainda segundo se prevê, para assegurar os benefícios do saneamento à totalidade da população, o sistema estadual deverá contar com mecanismos institucionais e financeiros que permitam a ação articulada e integrada entre o estado e os municípios. Cabe ao estado garantir a implantação de serviços de saneamento, em todo o território, mediante ação articulada com os municípios e a União; garantir aos municípios com baixa densidade populacional prioridade no planejamento e execução de obras com tecnologias alternativas; e, juntamente com os municípios, garantir à população rural atendimento que possibilite a equidade de acesso. 
Por plano estadual entende-se o conjunto de elementos de informação, diagnóstico, definição de objetivos, metas e instrumentos, programas, que integram o planejamento e a execução das ações de saneamento no estado. O plano será quadrienal e aprovado por lei.

O Fundo Estadual de Saneamento (Fesan) é o "instrumento institucional de caráter financeiro destinado a reunir e canalizar recursos para a execução dos programas do Plano Estadual de Saneamento", e deverá ser aprovado por lei. Quanto aos recursos do Fesan, serão aplicados em financiamentos com taxa de retorno não inferior à remuneração das contas do FGTS, mas a concessão de subsídios ou a destinação de recursos a fundo perdido dependerão da comprovação de interesse público relevante e de riscos elevados à saúde ou à segurança pública.

Como organismos de controle social do sistema estadual foram criados o Conselho Estadual de Saneamento (Conesan) e as comissões regionais de saneamento (Cresans). Entre as principais funções do conselho estadual estão a discussão e aprovação de propostas de projetos de lei referentes ao plano estadual e o exercício de funções normativas e deliberativas relativas à formulação, implantação e acompanhamento da política estadual. Conforme observado, o Conesan e as Cresans foram regulamentados pelo Decreto no 43.673, de 14 de março de 2005.

Na regulação, a política considera parte do seu sistema o órgão regulador estadual, embora a regulação não seja tratada especificamente na política. A Lei Estadual no 10.931, de 9 de janeiro de 1997, que cria a agência de regulação do estado do Rio Grande do Sul (Agergs), estabelece como competência da agência a regulação na área de saneamento.

\section{Rio Grande do Norte}

A política pública do estado do Rio Grande do Norte para o abastecimento de água e esgotamento sanitário define como princípio a universalização da prestação dos serviços. Entre os objetivos da política está o de ampliar os serviços de esgotamento sanitário aos mesmos percentuais do abastecimento de água e que nunca seja inferior a $90 \%$ da população do estado. Como principais instrumentos da política estadual mencionam-se o plano e o fundo estaduais de saneamento básico (Rio Grande do Norte, 2004).

De acordo com o disposto no plano estadual, a meta é atender com abastecimento de água tratada 100\% do universo da população urbana dos municípios concedentes em até cinco anos. Quanto ao esgotamento sanitário, 
estabelece-se o mínimo de $40 \%$ do universo da população urbana dos municípios concedentes, em até cinco anos; no mínimo 70\% em até 10 anos; e 100\% em até 15 anos. Conforme previsto, o plano deverá ser aprovado por lei, devendo constar do diagnóstico da situação atual dos sistemas de abastecimento de água e esgotamento sanitário os seguintes dados: indicativos sobre a necessidade e a quantificação dos investimentos; estabelecimento do cronograma físico-financeiro de sua execução e desembolso; marco regulatório, formado pelo conjunto das normas e atos jurídicos necessários para a disciplina; e o sistema de informações e controles, entre outros.

O Fundo Estadual de Saneamento Básico (Funesan), instrumento financeiro da política, tem o objetivo de assegurar os meios financeiros para aplicação exclusiva nas ações relativas ao abastecimento de água, esgotamento sanitário e reuso das águas, com prioridade para aquelas do plano estadual. $\mathrm{O}$ Funesan é constituído por 1\% dos recursos do Tesouro estadual; $5 \%$ da receita tarifária da Companhia de Águas e Esgoto do Rio Grande do Norte (Caern); doações de qualquer natureza; e outras receitas ou dotações orçamentárias que lhe vierem a ser destinadas. A administração do fundo é de responsabilidade da Caern.

Como objetivos da política estadual, sobressaem o estímulo à regulação e o controle da prestação dos serviços. Os municípios concedentes são considerados entes reguladores mediatos em relação à adoção de medidas de sua competência administrativa para o atendimento dos objetivos da política estadual.

\section{Goiás}

Nesse estado, o marco regulatório dos serviços de abastecimento de água e esgotamento sanitário tem por objetivo assegurar os benefícios da salubridade ambiental à totalidade da população do estado de Goiás. A universalidade, entendida como a garantia de oferta e de acesso aos serviços de abastecimento de água e esgotamento sanitário a toda a comunidade urbana constitui princípio fundamental e diretriz do marco regulatório (Goiás, 2004).

Para atender os usuários que não têm capacidade econômica de pagar integralmente os custos dos serviços, o poder público instituirá instrumentos financeiros tais como mecanismos e fontes de subsídios ou subvenções ao consumo ou investimentos por meio de fundos que forem criados pelos municípios. 
Como instrumento de controle social e regulação estão previstas a atuação do Conselho Estadual de Saneamento (Cesan), da Agência Goiana de Regulação, Controle e Fiscalização de Serviços Públicos (AGR) e das entidades reguladoras e fiscalizadoras municipais.

Entre as principais atividades do Cesan consta a aprovação do Plano de Gestão do Prestador (PGP), mediante parecer da AGR. O PGP deverá incluir um cronograma detalhado de metas de expansão dos serviços e de diversos indicadores de desempenho, que permitam avaliar a eficiência do prestador e dos serviços prestados, bem como o cronograma de investimentos e outras medidas a implementar para o atendimento dos objetivos. Ademais, o procedimento para a fixação das tarifas dos serviços de abastecimento e esgotamento sanitário passa pela aprovação e homologação do Cesan, após análise da AGR.

Compete às entidades reguladoras e fiscalizadoras exigir o cumprimento do PGP, controlar e fiscalizar a prestação dos serviços no âmbito de suas competências, regulamentar os serviços, aplicar sanções aos infratores, intervir na aprovação das tarifas, entre outros.

\section{Discussão}

Foi possível identificar cinco políticas públicas estaduais de saneamento básico de um total de 26 estados. A tabela 2 sumariza os resultados do estudo das cinco políticas em relação às quatro funções analisadas.

Tabela 2

Resumo das políticas estaduais de água e esgoto

\begin{tabular}{|llccccc|}
\hline \multirow{2}{*}{ Função } & \multirow{2}{*}{ Dispositivo } & \multicolumn{5}{c|}{ Políticas estaduais } \\
\cline { 3 - 7 } & & SP & MG & RS & RN & GO \\
\hline Universalização & Metas definidas & - & - & - & $\checkmark$ & - \\
Instrumentos financeiros & Fundo estadual & $\checkmark$ & $(2)$ & $\checkmark$ & $\checkmark$ & - \\
Regulação & Agência reguladora & $(1)$ & - & $(3)$ & - & $\checkmark$ \\
Controle social & Conselho estadual & $\checkmark$ & $\checkmark$ & $\checkmark$ & - & $\checkmark$ \\
& Conselho regional & $\checkmark$ & - & $\checkmark$ & - & $\checkmark$ \\
\hline
\end{tabular}

Legenda: $\boldsymbol{V}=$ presente; $-=$ ausente.

Obs.: (1) Não prevista na política. A comissão de regulação de São Paulo somente foi instituída em 2006 tendo como um dos objetivos o estudo de uma agência reguladora para o estado. (2) Embora originalmente previsto na política, o fundo estadual foi extinto em 2001. (3) A agência reguladora estadual foi criada em lei específica, anterior à edição da política. 
As cinco políticas públicas estaduais descritas consideram a universalização dos serviços de água e esgoto como princípio comum a ser atendido, entretanto somente a política do Rio Grande do Norte apresenta metas graduais com prazos definidos para universalização.

De acordo com estudos do Ministério das Cidades serão necessários cerca de R $\$ 178$ bilhões de investimentos para universalização dos serviços de água e esgoto no país até o ano de 2020 (Brasil, 2003), com os cinco estados representando R $\$ 78,5$ bilhões (tabela 1 ), $44,5 \%$ do total a ser investido. Ainda conforme esses estudos (Brasil, 2003:10) a universalização ocorre quando

a oferta atende a $100 \%$ da demanda, isto é, o serviço estará universalizado quando toda a população estiver atendida, segundo um determinado padrão de atendimento previamente estabelecido, considerando os diferentes usos dos serviços, não só nas casas, mas também no comércio, serviços, indústria e atividades públicas.

Em referência à universalização, a Conferência Pan-Americana sobre Saúde e Ambiente no Desenvolvimento Humano Sustentável (Brasil, 1995b) apresentou um conceito mais relacionado a equidade, definido como a extensão para toda a população do acesso a bens e serviços, independentemente dos vínculos de contribuição financeira e das condições socioeconômicas de cada indivíduo.

Com efeito, o conceito de universalidade do acesso aos serviços de água e esgoto não é um problema de natureza apenas econômica e técnica, mas principalmente social e política. São questões que passam pela redefinição do papel do Estado, por políticas de redistribuição de renda, e inclusive por mudança na forma de se compreender e fazer saúde pública.

O grande desafio para a universalização dos serviços está relacionado, sobretudo, ao equacionamento dos recursos para investimentos e operação e manutenção dos serviços, ou seja, quem pagará pela universalização dos serviços? Para Seroa da Mota (2004), esta questão pode ser resolvida com esquemas de subsídios sociais e não mediante subsídios tarifários cruzados. Já Turolla (2002) aponta para a constituição de um fundo de universalização em cada área de concessão dos serviços, composto de um percentual arrecadado sobre a receita bruta operacional dos prestadores de serviço. Além disso, estudo do governo de São Paulo reconhece que um obstáculo para a universalização é a não possibilidade de uma grande fração da população poder pagar pelos serviços de saneamento caso a tarifa recupere os investimentos e 
mantenha o sistema (São Paulo, 2003). Na opinião de Arretche (2004), diante do expressivo volume de recursos necessários, é reduzido o número de estados e municípios capazes de implementar políticas efetivas de saneamento, sem aportes federais.

Dos instrumentos financeiros das políticas, somente o estado de Goiás não estruturou um Fundo Estadual de Saneamento, apesar de o estado de Minas Gerais ter constituído originalmente o fundo e o revogado posteriormente. Por falta de regulamentação não há expectativa quanto à suficiência dos recursos a serem arrecadados pelos fundos de São Paulo e Rio Grande do Sul para atender parcela dos investimentos demandados para a universalização nesses estados. Ademais, a não previsão de parte da receita orçamentária do prestador de serviços estadual como componente dos fundos, nos moldes do estado do Rio Grande do Norte, limita a maior capacidade de intervenção da política estadual na universalização dos serviços.

Apesar de a previsão da receita orçamentária do prestador de serviços estadual como componente dos fundos está determinada somente para o estado do Rio Grande do Norte, em geral os executores das políticas são as próprias companhias estaduais de saneamento básico. Segundo Faria e Faria (2004), os prestadores de serviço no país não têm condições de operar os serviços de forma autônoma e sem transferências da União, ou dos estados, a fundo perdido. Portanto, é indispensável a reconstrução do modelo de financiamento para o setor. Já Turolla (2002) propõe a utilização de parcerias com o setor privado na realização de investimentos e na operação dos sistemas de saneamento, mas ressalta a necessidade da definição do marco legal. Entretanto, a participação do setor privado e tarifas que reflitam custos reais poderão excluir parcela da população do acesso aos serviços, caso essas medidas não sejam acompanhadas por políticas de subsídios sociais e diretos aos usuários, cuja definição passa necessariamente por uma ação de Estado por meio de políticas públicas.

Mesmo equacionando-se os investimentos para o setor, outro grande desafio é a melhoria da gestão dos serviços, caracterizada por ineficiência operacional, elevados níveis de perdas e falta de planejamento. Teixeira e Heller (2001) corroboram essa afirmação, ressaltando ser fundamental o planejamento como instrumento para evitar uma alocação ineficiente dos recursos disponíveis, na qual a decisão "de onde investir", "em que investir" e "o quanto investir" deve ser tomada com bases racionais. De acordo com os dados, somente $20 \%$ da capacidade instalada de tratamento de esgotos no país são utilizados, como resultado de um planejamento deficiente (Margulis et al., 2002). Particularmente, no âmbito dos estados, uma pesquisa identificou ser 
preciso reduzir a distância entre a política setorial e sua implementação, pois apenas 34\% dos estados brasileiros afirmaram fazer a coordenação entre o planejamento geral e os setoriais (Abrucio, 2005).

Ao longo da última década, a regulação e o controle social têm sido um consenso no discurso dos atores políticos, como tema central para uma política pública nacional de água e esgoto, a despeito das divergentes posições de como deve ser essa regulação e controle social, e de que forma devem ser reproduzidos nas políticas estaduais. Quanto à regulação, diretrizes estabelecidas no projeto de lei que cria o marco regulatório do setor, aprovado pela Câmara dos Deputados em dezembro de 2006, oferecem um quadro geral dentro do qual a função regulatória deverá ser estabelecida, estimulando a cooperação entre entes federados no exercício dessa função.

Com exceção de Goiás nenhum estado apresenta uma política clara para a regulação dos serviços. Em Goiás, além de uma agência reguladora estadual, os municípios podem constituir entidades reguladoras locais. Um dos aspectos mais relevantes dessa regulação é o procedimento de aprovação das tarifas pelo Conselho Estadual de Saneamento após parecer da Agência Goiana de Regulação. Tal procedimento pode ser considerado inovador, visto que a contabilidade das concessionárias e a definição de tarifas são assuntos tratados de forma pouco transparente. Já em relação a São Paulo, o decreto de criação da Corsanpa apresenta falhas passíveis de comprometer a credibilidade e o futuro da regulação naquele estado. Por exemplo, não há previsão de taxa de regulação e a entidade reguladora está subordinada ao secretário de estado, cuja função é também a de presidir o conselho de administração da empresa estatal a ser regulada e fiscalizada. De acordo com Conforto (1998), o ente regulador deve ser constituído de forma a garantir sua relativa autonomia em relação aos interesses políticos imediatos e aos recursos de sua manutenção, e a preservá-lo em relação à captura pelo concessionário de serviços.

Dos cinco estados analisados, somente Goiás e Rio Grande do Sul apresentam agência reguladora estadual. Segundo Da Silva e colaboradores (2005), a alternativa de criação de entidades reguladoras autônomas municipais mostra-se demasiadamente onerosa para a maioria dos municípios. Resta-lhes a delegação dessa atividade a agências reguladoras estaduais.

No processo de mudanças em que se encontra o setor de saneamento no país, a questão da regulação é parte fundamental, pois implica a capacidade de gestão dos diferentes níveis de governo, definindo a forma pela qual se pode atingir uma eficiência de gestão e planejamento associada à compatibilidade econômica e financeira (Soares et al., 2003). Galvão Jr. e colaboradores (2006) corroboram essa posição, afirmando que o saneamento carece de uma 
cultura regulatória que envolva todos os atores (o poder concedente, o concessionário e o usuário) e que prime pela transparência e eficiência, com modicidade tarifária e participação na definição das políticas e prioridades (controle social). Sem embargo, um serviço essencial sob o regime de monopólio exige regulação bem estruturada a fim de garantir sua universalização e evitar que os cidadãos sejam privados do acesso ou paguem taxas excessivas pelos serviços prestados (Britto, 2001).

Das políticas analisadas, somente o Rio Grande do Norte não prevê a existência do controle social por meio de conselho de caráter deliberativo. Se, por um lado, faz-se necessário incrementar o exercício efetivo e o aprimoramento dessa atividade por parte dos conselhos estaduais, visto o setor não ter uma cultura de transparência e de participação da sociedade, por outro lado os críticos apontam a possibilidade de manipulação de decisões por entidades mais organizadas ou grupos políticos, contornando os mecanismos democráticos tradicionais e gerando oportunidades para setores sociais específicos em detrimento da população em geral. Outro aspecto relevante é a informação e capacitação dos atores diretamente envolvidos nos processos decisórios, sobretudo no âmbito dos colegiados (Pereira e Formiga-Johnsson, 2005). Além disso, como ressalta Conforto (1998), é preciso publicidade sobre os benefícios e metas contratados, parâmetros pretendidos, os direitos e as formas de atuação dos usuários, necessários para assegurar uma massa crítica capaz de intervir de forma efetiva no processo.

\section{Conclusão}

Há um grande desafio para a universalização dos serviços de água e esgoto. Essa é uma tarefa de responsabilidade das três esferas: União, estados e municípios. Para concretizá-la, principalmente quanto ao esgotamento sanitário, os investimentos necessários estão acima da capacidade do setor, e são indispensáveis recursos federais, estaduais, municipais e privados. Como mencionado, ausência de metas nas políticas públicas analisadas, excetuando o Rio Grande do Norte, dificulta o acompanhamento e a responsabilização de gestores públicos por parte da sociedade em virtude do não cumprimento da política.

Em face dos elevados investimentos exigidos para a universalização, os instrumentos financeiros devem ser consistentes para captação dos recursos e transparentes quanto aos critérios de aplicação. Apesar de algumas das políticas analisadas preverem a constituição de fundos de saneamento, eles são insuficientes para o atendimento das demandas da universalização. 
Outro aspecto negativo das políticas estudadas, exceto em Goiás, é a ausência de diretrizes efetivas para a regulação da prestação dos serviços. Da mesma forma, o controle social, embora previsto em quatro das cinco políticas estudadas, requer ser efetivamente praticado e incentivado para que o setor se torne mais transparente e eficiente, considerando-se inclusive os riscos inerentes ao que se convencionou chamar de controle social.

Algumas dificuldades adicionais dizem respeito à falta de regulamentação das políticas, como no caso de São Paulo e à implementação tempestiva das políticas. Esta última esbarra na ausência de uma estrutura operacional e capacitada no âmbito das secretarias dos estados às quais o saneamento básico está vinculado.

O levantamento apresentado neste artigo mostrou que o número de políticas estaduais é ainda inexpressivo diante da quantidade de estados e dos desafios postos para o setor. Entretanto, a aprovação de lei federal, em dezembro de $2006,{ }^{3}$ contendo diretrizes para a regulação e as políticas públicas, deverá contribuir no futuro para a disseminação dos marcos subnacionais, tanto estaduais quanto até mesmo municipais.

\section{Referências bibliográficas}

ABRUCIO, F. L. Reforma do Estado no federalismo brasileiro: a situação das administrações públicas estaduais. Revista de Administração Pública, Rio de Janeiro, v. 39, n. 2, p. 401-420, mar./abr. 2005.

ARRETCHE, M. Federalismo e políticas sociais no Brasil: problemas de coordenação e autonomia. São Paulo em Perspectiva, São Paulo, v. 18, n. 2, p. 17-26, abr./jun. 2004.

BRASIL. Ministério do Planejamento e Orçamento. Flexibilização institucional da prestação de serviços de saneamento. Brasília, DF, 1995a.

. Ministério da Saúde. Plano Nacional de Saúde e Ambiente no Desenvolvimento Sustentável. Brasília, DF, 1995b.

. Ministério das Cidades. Secretaria Nacional de Saneamento Ambiental. Dimensionamento das necessidades de investimento para a universalização dos serviços de abastecimento de água e de coleta e tratamento de esgotos sanitários no Brasil. Brasília, DF, 2003.

\footnotetext{
${ }^{3}$ Pendente de sanção presidencial no momento em que este artigo foi finalizado.
} 
BRITTO, A. L. N. P. A. Regulação dos serviços de saneamento no Brasil: perspectiva histórica, contexto atual e novas exigências de uma regulação pública. In: ENCONTRO NACIONAL DA ANPUR, 9., 2001, Rio de Janeiro. Anais... Rio de Janeiro: Anpur, 2001. p. 1080-1093.

CONFORTO, G. Descentralização e regulação da gestão de serviços públicos. Revista de Administração Pública, Rio de Janeiro, v. 32, n. 1, p. 27-40, jan./fev. 1998.

COSTA, A. M. Avaliação da política nacional de saneamento, Brasil - 1996/2000. 2003. Tese (Doutorado em Saúde Pública) — Escola Nacional de Saúde Pública, Fiocruz, Recife.

DA SILVA, A. C. et al. Regulação municipal por uma agência reguladora estadual. In: CONGRESSO BRASILEIRO DE ENGENHARIA SANITÁRIA E AMBIENTAL, 23., 2005, Campo Grande. Anais... Rio de Janeiro: Abes, 2005.

FARIA, S. A.; FARIA, R. C. Cenários e perspectivas para o setor de saneamento e sua interface com os recursos hídricos. Eng. San. Ambiental, Rio de Janeiro, v. 9, n. 3, p. 202-210, jul./set. 2004.

GALVÃO JR., A. C. et al. Regulação — procedimentos de fiscalização em sistemas de abastecimento de água. Fortaleza: Expressão Gráfica Ltda./Arce, 2006.

GOIÁs. Lei Estadual n. 14.939, de 15 de setembro de 2004. Institui o Marco Regulatório da Prestação de Serviços de Abastecimento de Água e Esgotamento Sanitário, cria o Conselho Estadual de Saneamento - Cesan e dá outras providências. Disponível em: <www.gabinetecivil.goias.gov.br/> . Acesso em: 29 maio 2006.

IBGE (Instituto Brasileiro de Geografia e Estatística). Síntese de Indicadores Sociais 2004. Rio de Janeiro, 2005. 2006. Estados@. Disponível em: <www.ibge.gov.br>. Acesso em: 28 maio

MARGULIS, S. et al. Brasil: a gestão da qualidade da água. Brasília: Banco Mundial, 2002.

MINAS GERAIS. Lei Estadual n. 11.720, de 29 de dezembro de 1994. Dispõe sobre a Política de Saneamento Básico e dá outras providências. Disponível em: <www. almg.gov.br/>. Acesso em: 29 maio 2006.

MORAES L. R. S.; BORJA, P. C. Política e regulamentação do saneamento na Bahia: situação atual e necessidade de arcabouço jurídico-institucional. In: CONGRESSO BRASILEIRO DE ENGENHARIA SANITÁRIA E AMBIENTAL, 21., 2001, João Pessoa. Anais... Rio de Janeiro: Abes, 2001.

MOTA, R. Seroa da. Questões regulatórias do setor de saneamento no Brasil. Brasília: Ipea, 2004. 
NASCIMENTO, N. O.; HELLER, L. Ciência, tecnologia e inovação na interface entre as áreas de recursos hídricos e saneamento. Eng. San. Ambiental, Rio de Janeiro, v. 10, n. 1, p. 36-48, jan./mar. 2005.

OGERA, R. C.; PHILIPPI JR., A. Gestão dos serviços de água e esgoto nos municípios de Campinas, Santo André, São José dos Campos e Santos, no período de 1996 a 2000. Eng. San. Ambiental, Rio de Janeiro, v. 10, n. 1, p. 72-81, jan./mar. 2005.

OLIVEIRA, C. T.; SANCHEZ, O. A. Descentralização e saneamento básico no estado de São Paulo. Debates Socioambientais, Cedec, ano I, n. 3., fev./mar./abr./maio 1996.

PEREIRA, P. S. P; FORMIGA-JOHNSSON, R. M. Descentralização da gestão dos recursos hídricos em bacias nacionais no Brasil. Revista de Gestão de Água da América Latina, Porto Alegre, v. 2, n. 1, p. 53-72, jan./jun. 2005.

RIO GRANDE DO NORTE. Lei Estadual n. 8.485, de 20 de fevereiro de 2004. Dispõe sobre a política estadual de saneamento básico, institui o Sistema Integrado de Gestão do Esgotamento Sanitário e dá outras providências. Disponível em: <www. gabinetecivil.rn.gov.br/acess/pdf/lo8.485.pdf>. Acesso em: 29 maio 2006.

RIO GRANDE DO SUL. Lei Estadual n. 12.037, de 19 de dezembro de 2003. Dispõe sobre a política estadual de saneamento e dá outras providências. Disponível em: $<$ www.al.rs.gov.br/>. Acesso em: 29 maio 2006.

SÃO PAULO. Lei Estadual n. 7.750, de 31 de março de 1992. Dispõe sobre a política Estadual de Saneamento e dá outras providências. Disponível em: <www. recursoshidricos.sp.gov.br/Legislacao/Lei_Est_7750.html>. Acesso em: 29 maio 2006.

. Secretaria de Energia, Recursos Hídricos e Saneamento - Coordenadoria de Saneamento. Estudo para o Desenvolvimento de Estratégias para a Universalização dos Serviços no Setor de Saneamento Básico do Estado de São Paulo, em Conformidade com a Lei $n$. 7.750/92 - Termo de referência, 2003. Disponível em: <ftp://ftp. sp.gov.br/ftphidricos/Diversos_San/TR_Univ.PDF>. Acesso em: 29 maio 2006.

. Decreto n. 50.868, de 8 de junho de 2006. Institui a Comissão de Regulação do Serviço de Saneamento do Estado de São Paulo - Corsanpa. Diário Oficial do Estado de São Paulo, São Paulo, 9 jun. 2006. Seção I.

SOARES, S. R. A.; NETTO, O. M. C.; BERNARDES, R. S. Avaliação de aspectos políticos institucionais e econômico-financeiros do setor de saneamento no Brasil com vistas à definição de elementos para um modelo conceitual. Eng. San. Ambiental, Rio de Janeiro, v. 8, n. 1/2, p. 84-94, jan./jun. 2003. 
TEIXEIRA, J. C., HELLER, L. Estudo comparativo entre o processo de planejamento nos setores de saúde e de saneamento no Brasil. In: CONGRESSO BRASILEIRO DE ENGENHARIA SANITÁRIA E AMBIENTAL, 21., 2001, João Pessoa. Anais... Rio de Janeiro: Abes, 2001.

TUROLLA, F. A. Provisão e operação de infra-estrutura no Brasil: o setor de saneamento. Dissertação (Mestrado em Economia de Empresas) — Fundação Getulio Vargas, São Paulo, 1999.

. Política de saneamento: avanços recentes e opções futuras de políticas públicas. Brasília: Ipea, 2002. (Texto para Discussão, n. 922).

WHITAKER, P. P. Abastecimento de água potável às cidades: problemas que se apresentam nesse campo em nosso país. Revista Engenharia. São Paulo: Pini, dez. 1991. 